\title{
VIABILIDADE PARA O CULTIVO DE SOJA DEVIDO AS RELAÇÕES TÉRMICAS E HÍDRICAS NA BACIA DO RIO IPIRANGA NO MUNICÍPIO DE SANTA TEREZINHA DO ITAIPU ${ }^{1}$
}

Alisson Rodrigues Alvez ${ }^{2}$, Elisandro Pires Frigo ${ }^{3}$, Cristiano de Assumpção Santos ${ }^{4}$, Carlos Henrique Fornasari ${ }^{5}$, Alvaro Mari Junior ${ }^{6}$, Angelo Gabriel Mari ${ }^{7}$

\footnotetext{
${ }^{1}$ Artigo aceito no $3^{\circ}$ semestre de 2013

${ }^{2}$ Engenheiro Ambiental, alisson.tutor@gmail.com ;

${ }^{3}$ Doutor em Irrigação e Drenagem, epfrigo@ufpr.br;

${ }^{4}$ Engenheiro de Produção, cristianoassump@ hotmail.com;

5 Engenheiro Agrônomo, carlos_fornasari@hotmail.com;

${ }^{6}$ Engenheiro Ambiental, professor.alvaro.mari@gmail.com;

${ }^{7}$ Engenheiro Ambiental, ea.angelo@gmail.com.
}

Palavras-chave: Morfometria, bacia hidrográfica, balanço hídrico, soja.

\section{Resumo}

O presente trabalho tem como objetivo descrever a caracterização morfométrica da bacia hidrográfica do Rio Ipiranga localizada no município de Santa Terezinha do Itaipu no Estado do Paraná e realizar o zoneamento climático para a região de estudo, para definir a viabilidade para o cultivo da soja com relação as condições térmicas e hídricas exigidas pela cultura buscando a maximização da produtividade regional para atender a crescente demanda por produtos alimentícios. Santa Terezinha de Itaipu fica a $619 \mathrm{~km}$ da Capital do Estado, Curitiba, via BR 277. Situa-se na região Oeste do Paraná possuindo um território com 259 $\mathrm{km}^{2}$, o método utilizado para realizar o estudo do balanço hídrico da região foi o método de Thornthwaite \& Mather. Considerando as exigências térmicas e hídrica da soja fica evidente que, para garantir máximo rendimento de grãos, o volume de água necessário deve ser disponibilizado ao longo de todo o ciclo, a fim de atender as exigências da cultura, podendo ser suprido através da chuva, da irrigação e/ou do armazenamento de água pelo solo. Este trabalho conclui que o município estudado revela-se apto para o cultivo de soja precoce e/ou tardia em relação às necessidades térmicas e hídricas, pois, todos os parâmetros são atendidos de acordo com o balanço hídrico da região de estudo. 


\title{
VIABILITY FOR GROWING SOYBEANS BECAUSE RELATIONS THERMAL AND HYDRO IPIRANGA RIVER BASIN IN THE CITY OF ST. TEREZINHA OF THE ITAIPU
}

Key words: Morphometric, hydrographic, swing, water, soy.

\begin{abstract}
The present work aims describe the morphometric characterization of Ipiranga river basin located the city of St. Terezinha of the Itaipu State of Paraná and perform zoning climate for the study area, to define the feasibility of soybean cultivation with respect to temperature and humidity conditions required by culture seeking to maximize regional productivity to meet growing demand for food products.St. Terezinha of Itaipu is $619 \mathrm{~km}$ from the state capital, Curitiba, via BR 277. it is located in western Paraná possessing a territory of $259 \mathrm{~km}^{2}$, the method used to conduct the study of hydric balance region was the method of Thornthwaite \& Mather. Considering the demands thermal and hydro soybean is evident that to ensure maximum yield, the volume of water necessary should be provided along the entire cycle in order to meet the crop requirements and can be supplied through the rain, irrigation and/or soil water storage. This paper concludes that the municipality studied proves to be suitable for the cultivation of early soybean and/or late in relation to the needs temperature and humidity, because all parameters are met in accordance with the hydric balance of the study area.
\end{abstract}

\section{Introdução}

Bacia hidrográfica define-se hoje como uma das referências espaciais de amplo estudo na área físico-territoriais ou de projetos, não só em relação as suas características naturais, mas por a mesma estar de forma significativa, presente em legislação vigente quando se trata do meio ambiente, fazendo parte, portanto, do planejamento territorial e ambiental no Brasil (Rodrigues e Adadi, 2005).

Nos estudos de bacias hidrográficas, bem como em seu gerenciamento, o solo é um dos elementos mais importantes, pois é devido a sua distribuição na bacia e a sua grande interação com os recursos hídricos que as atividades humanas são regidas. Os efeitos do uso inadequado dos solos podem ser percebidos em rios e lagos, devido ao carreamento de partículas na estação chuvosa, efeito ainda maior no nível das bacias (Schiavetti, 2003). 
Dentro desta perspectiva a caracterização morfométrica de uma bacia hidrográfica faz parte essencial do desenvolvimento da região abrangida por ela.

As características físicas e bióticas das Bacias Hidrográficas desempenham papel importante no seu comportamento hidrológico, sendo primordial o acompanhamento numérico do sistema, utilizando os dados mensurados para avaliar se as culturas atuais da bacia são as que melhor aproveitam a sua tipologia hidrológica buscando alcançar seu potencial máximo de rendimento.

De acordo com Silva et al., (2006), a soja (Glycine max) é uma matéria prima de grande interesse mundial devido à versatilidade do seu uso na alimentação humana e animal, e ao seu valor econômico agregado no mercado nacional e internacional. O Brasil se classifica entre os maiores produtores de soja do mundo, sendo uma espécie cultivada em diversas regiões do País.

O déficit hídrico, habitualmente, é o principal parâmetro responsável por perdas de produtividade na lavoura. Como exemplo, pode-se citar as estiagens ocorridas nas safras 1977/1978 e 1978/1979, nos Estados da Região Sul do Brasil (perdas médias de $32 \%$ ao ano), deixou-se de colher cerca de 7,2 milhões de toneladas de grãos de soja, isto é, aproximadamente 1,5 bilhões de dólares (FARIAS et al., 1993).

O balanço hídrico climatológico, desenvolvido por Thornthwaite \& Mather (1955) é uma das inúmeras maneiras de acompanhar a variação do armazenamento de água no solo. Através da mensuração do suprimento natural de água ao solo, pela chuva $(\mathrm{P})$, e da demanda atmosférica, pela evapotranspiração potencial (ETP), e com a capacidade de água disponível (CAD) apropriada ao estudo em questão, o balanço hídrico fornece estimativas da evapotranspiração real (ETR), da deficiência hídrica (DEF), do excedente hídrico (EXC) e do armazenamento de água no solo (ARM), podendo ser gerado desde a escala diária até a mensal (Camargo, 1971; Pereira et al., 1997).

O balanço hídrico climatológico é mais comumente apresentado na escala mensal e para um ano médio. De acordo com Camargo \& Camargo (1993), o balanço hídrico climatológico é uma ferramenta da agrometeorologia útil e prática para mensurar o parâmetro umidade do clima, sendo sua utilização indispensável na caracterização climática (Vianello \& Alves, 1991; Pedro Júnior et al., 1994) como, também, na definição da aptidão agrícola da região estudada (Ortolani et al., 1970; Camargo et al., 1974). O balanço hídrico de Thornthwaite \& Mather (1955), além dessas aplicações, quando empregado de maneira sequencial, ainda possibilita quantificar as necessidades de irrigação em uma cultura 
(Camargo \& Pereira, 1990) e a relacionar o rendimento das culturas com o déficit hídrico (Jensen, 1968; Doorenbos \& Kassam, 1994).

Diante o exposto, este trabalho tem como objetivo descrever a caracterização morfométrica da bacia hidrográfica do Rio Ipiranga localizada no município de Santa Terezinha do Itaipu no Estado do Paraná e realizar o zoneamento climático para a região de estudo, para definir a viabilidade para o cultivo da soja com relação as condições térmicas e hídricas exigidas pela cultura buscando a maximização da produtividade regional para atender a crescente demanda por produtos alimentícios.

\section{Material e Métodos}

Caracterização da área de estudo:

De acordo com o diagnóstico local do município 2007, Santa Terezinha de Itaipu fica a 619 km da Capital do Estado, Curitiba, via BR 277. Situa-se na região Oeste do Paraná possuindo um território com $259 \mathrm{~km}^{2}$ representando $0.1301 \%$ do Estado, $0.046 \%$ da Região e $0.0031 \%$ de todo o território brasileiro. Seus limites são: ao norte o Lago de Itaipu, com divisa internacional com a República do Paraguai; ao sul, o Parque Nacional do Iguaçu; a leste, São Miguel do Iguaçu; a oeste, Foz do Iguaçu. Está a $21 \mathrm{~km}$ do centro de Foz do Iguaçu, pela rodovia BR 277 e a 17 km de São Miguel do Iguaçu, também pela BR 277. O município tem o clima subtropical úmido mesotérmico, a topografia é predominantemente plana. A altitude média é de 320 metros. A latitude é de $25^{\circ} 25^{\prime} 00^{\prime}$ sul e a longitude, $54^{\circ} 25^{\prime} 00^{\prime \prime} \mathrm{W}$ - GR. A bacia hidrográfica da região é composta pelos rios: Bacia do Rio Tamanduá, Rio Ipiranga, Rio São João e Vitorassi.

O município de Santa Terezinha de Itaipu se encontra na Mesorregião Oeste Paranaense e seu território faz parte do Terceiro Planalto Paranaense, também conhecido como Arenito-Basáltico, por ser constituído de arenitos paleozóicos recobertos na Era Mesozóica por grande quantidade de lavas vulcânicas, rochas magmáticas extrusivas que deram origem ao fértil solo de terra roxa da região (PALHARES, 2000).

Para caracterização da bacia hidrográfica do Rio Ipiranga foram utilizados ferramentas de geoprocessamento baseados em tecnologia livre (gvSig e SPRING), auxiliando na tomada de decisões para investigação de pontos críticos, levando em consideração que o estudo necessita do levantamento total da superfície territorial da bacia.

As imagens de satélites representam importante fonte de informação para trabalhos que envolvem geoprocessamento e sensoriamento remoto. Sua utilização em Sistemas de 
Informações Geográficas - SIG incrementa bancos de dados geográficos, permitindo a geração de informações sobre diferentes aspectos do meio natural e antrópico, bem como analises ambientais.

Através destes produtos manipulados em SIG, pode-se representar informações geológicas, geomorfológicas, do uso e ocupação do solo, bem como trabalhar na investigação dos plantéis produtivos, inclusive de animais.

Assim, visando complementar as informações geográficas que estão sendo utilizadas neste estudo, foram obtidas imagens do satélite CBERS-2B, que após fusionadas serviram ao mapeamento do uso do solo na microbacia do Rio Ipiranga, e à definição de sua estrutura fundiária.

\section{Elaboração do banco de dados do balanço hídrico climatológico:}

Os balanços hídricos foram calculados em planilha EXCEL elaborada para tal finalidade por Rolim et al. (1998), aplicando-se o método de Thornthwaite \& Mather (1955) para uma capacidade de água disponível (CAD) de $100 \mathrm{~mm}$ que pode ser considerado uma aproximação razoável para as culturas agrícolas comuns, segundo Mota (1977), com a evapotranspiração potencial (ETP) sendo estimada pelo método de Thornthwaite (1948). Os dados normais de temperatura média mensal do ar (TMED) e chuva total média mensal (P) utilizados neste banco de dados são pertencentes às redes do INMET, IAC, IAPAR, DAEE/SP e ESALQ/USP e são do município de Foz do Iguaçu, localizado a $21 \mathrm{~km}$ de distância do município de Santa Terezinha de Itaipu. Os dados apresentam as estimativas da evapotranspiração real (ETR), armazenamento de água no solo (ARM), deficiência hídrica (DEF) e excedente hídrico (EXC), na escala mensal, sendo instrumento útil no planejamento das atividades agrícolas.

Foi realizado um levantamento a respeito das necessidades térmicas e hídricas da cultura considerada neste estudo para avaliar se a região é apta, ou inapta ao cultivo desta. Uma localidade é considerada apta quando as condições térmicas e hídricas da área apresentam-se favoráveis para o bom desenvolvimento e produção da cultura em escala econômica e inapta quando as características normais de clima apresentam grandes limitações às condições hídricas e/ou térmicas necessárias ao cultivo desta.

\section{Resultados e Discussão}

Caracterização da microbacia:

Revista Brasileira de Energias Renováveis, v. 4, p. 18-31, 2013 
A porção territorial definida pela área de drenagem do Rio Ipiranga, microbacia hidrográfica deste rio, situa-se na região centro norte do município de Santa Terezinha de Itaipu.

Em sua área de 1.181,3276 ha encontram-se distribuídos usos do solo em atividades agropecuárias (agricultura, pastagens, florestas nativas e exóticas, açudes e áreas de sede de propriedades rurais), e uma pequena área urbana ocupada pela zona industrial da cidade.

Devido as favoráveis condições naturais, herança da geologia e clima regional, extensas áreas da microbacia são compostas por solos do tipo Latosolo - altamente argiloso, permeável, profundo e com grande presença de macro e micronutrientes. Estas características associadas à baixa declividade das vertentes inseridas em um relevo suave ondulado, de geometria plana e levemente convexa, propiciaram um forte desenvolvimento da agricultura mecanizada. Em áreas de menor aptidão agrícola, desenvolvem-se outras atividades agropecuárias, voltadas a silvicultura, criação de rebanhos e tanques de piscicultura também se fazem presentes.

$\mathrm{Na}$ área urbana consolidada encontra-se parte do Distrito Industrial do município, zona onde estão instalados 63 empreendimentos, grande maioria em trâmite com processos de Licenciamento Ambiental devido aspectos negativos em suas atividades, como a manipulação de produtos químicos perigosos e a geração de efluentes sólidos, líquidos e gasosos.

Para complementar a caracterização física da microbacia, pode-se mencionar que seu escoamento é endorreico, com drenagens intra continental e deflúvio no lago de Itaipu, seu fator de forma, segundo Lima (1996) apud Horton (1932), é de 0,2446, resultado associado a áreas elipsoidais achatadas - bacias longas e estreitas com baixa susceptibilidade a inundação, devido as precipitações localizadas não serem interceptadas por grande área de drenagem, possui índice de circularidade conforme o mesmo autor apud CHISTOFOLETTI (1974), de 0,5335, valor que dá proximidade a um formato alongado (o valor máximo do índice é igual a 1 - este resultado descreve bacias circulares), e densidade de drenagem, apud Horton (1932) e Sthraler (1957), de 0,7955 km, considerada baixa, ocasionada por condições naturais do solo (permeabilidade) e as precipitações.

Quanto à hidrografia a rede de rios onde se faz presente o Rio Ipiranga caracteriza-se por uma formação dendrítica (organização de rios que lembram uma árvore), cujo tributário principal - Rio Ipiranga, é perene, de segunda ordem, e conta com uma extensão de $5.278,9068$ metros.

A fim de estabelecer seus limites geográficos, abaixo podemos observar o 
posicionamento da microbacia em relação ao município, bem como representa a hidrografia, altimetria e rede viária com ocorrência nas duas áreas, como pode ser observado na figura 01:

Figura 01: Mapa de caracterização da microbacia do Rio Ipiranga

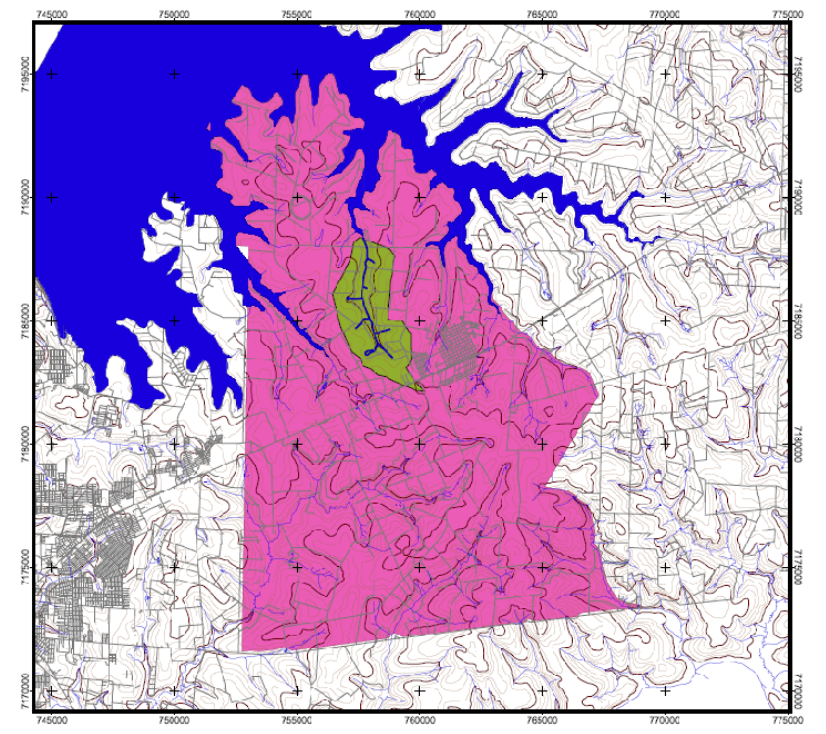

Legenda:

$\square$ Limite Município $\quad$ Curvas de Nível

$\square$ Divisores Interbacia $\sim$ Intermediarias

$\square$ Reservatório Itaipu $\quad$ Mestras

$\sim$ Hidrografia

Rede Viária

$\stackrel{\mathrm{\Lambda}}{\Lambda}$
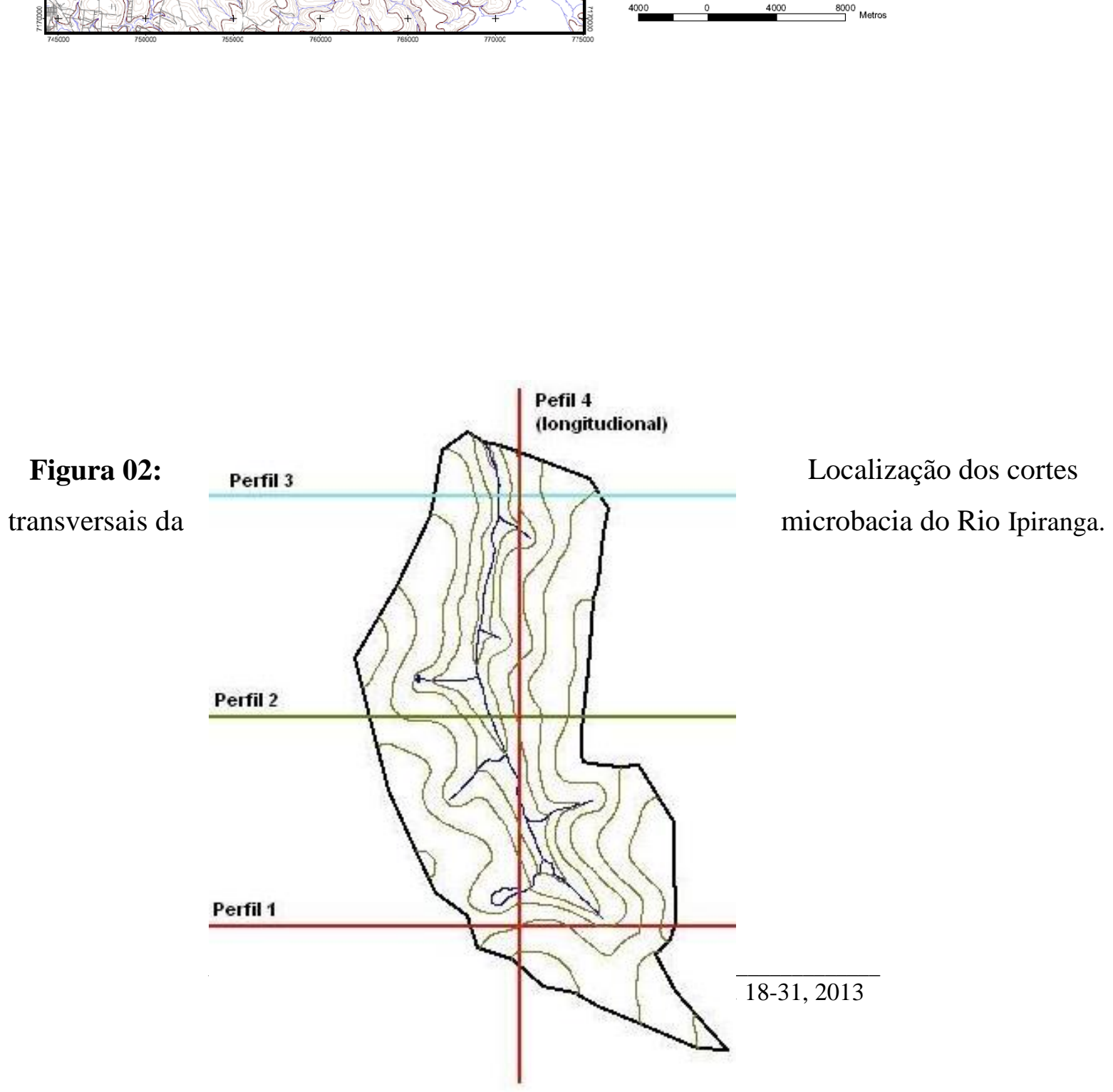
Figura 03: Perfis transversais da microbacia do Rio Ipiranga.

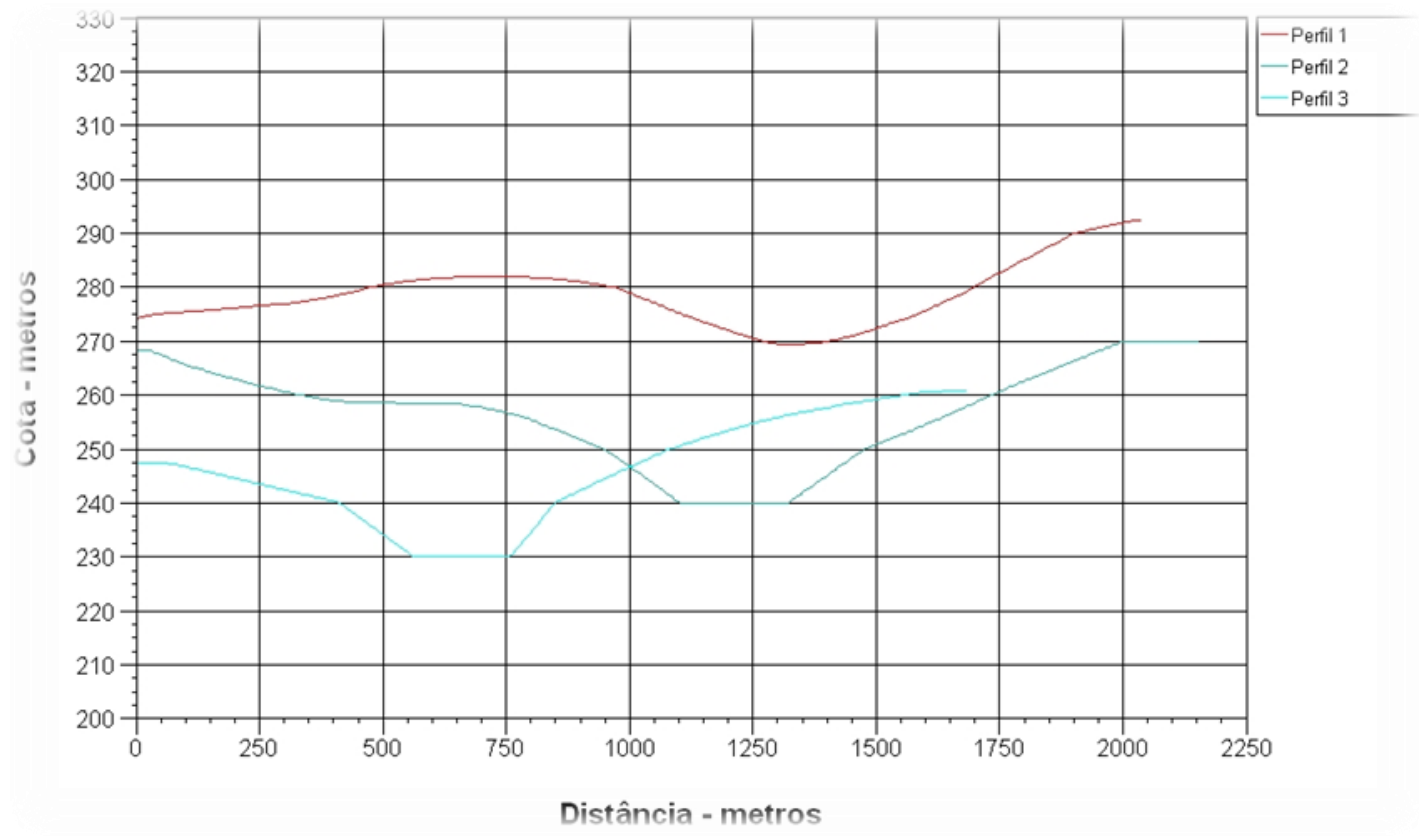

O perfil transversal permite perceber a declividade das encostas e o quão encaixado é o canal de drenagem do rio. De acordo com ele pode-se considerar que se trata de uma microbacia com desnível próximo a 50 metros entre a cabeceira de drenagem e sua foz, caracterizando uma rede de drenagem de pequena energia de escoamento hídrico. O perfil 2 descreve características de relevo, definido como suave ondulado, onde as colinas são largas, apresentando superfícies de até 1000 metros, conforme se observa entre as distancias de 1125 e 2125 metros, que são modeladas em desníveis não superiores a 30 metros, cota 270 a 230. Essas características naturais estão associadas à microbacias com baixo potencial de degradação ambiental.

O perfil longitudinal da microbacia explicita a declividade do talvegue e ilustra 
características do rio, como a localização de possíveis quedas e remansos. Este perfil é apresentado abaixo, na figura 04 .

Figura 04: Perfil longitudinal da microbacia hidrográfica do Rio Ipiranga.

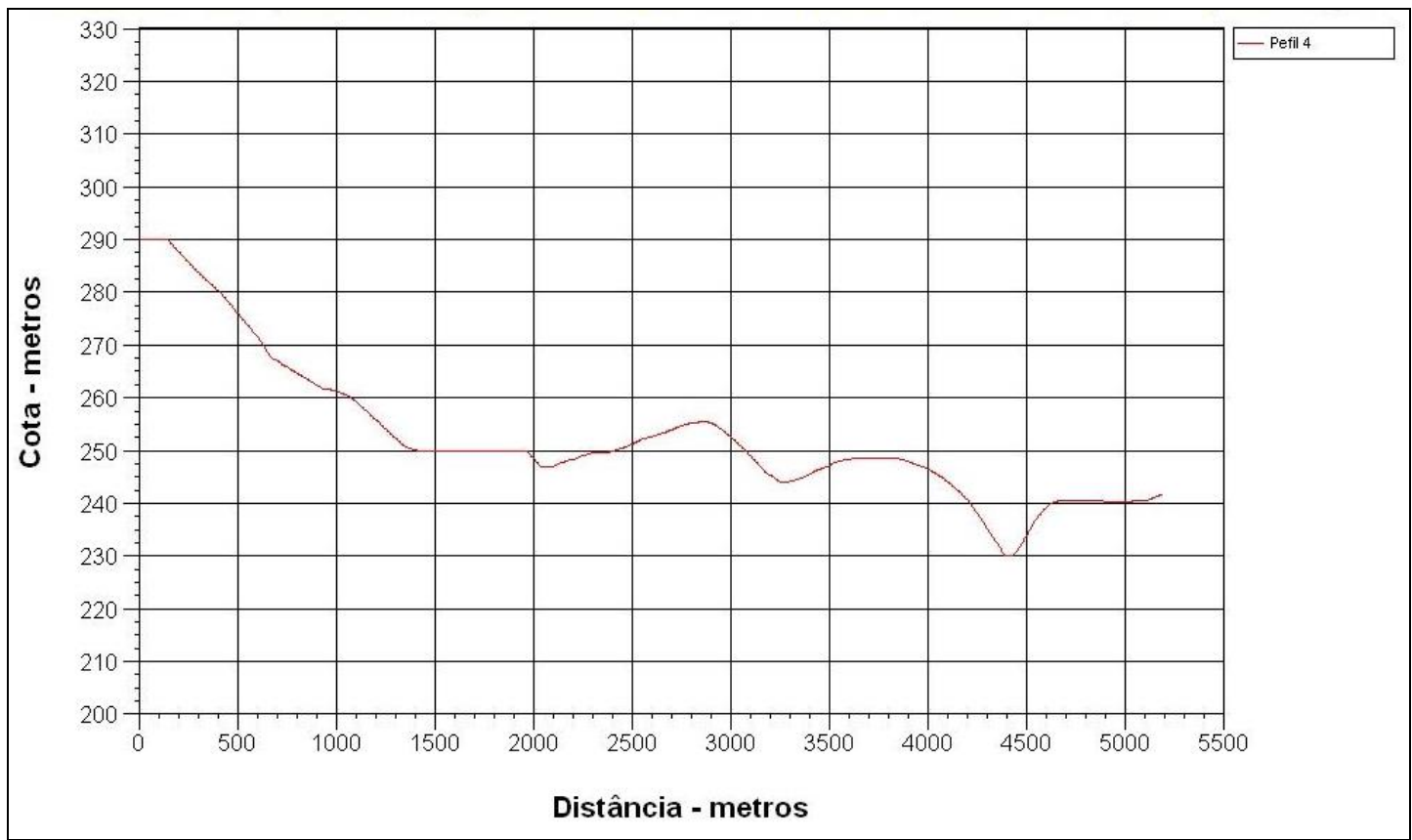

Pode-se observar que a microbacia possui um talvegue de inclinação suave, e consequentemente águas calmas, não existindo corredeiras, com maior energia em sua cabeceira de drenagem, onde existe um declive mais acentuado.

Segundo Rosa e Brito (2003), os estudos hipsométricos permitem conhecer o relevo e detectar seu índice de dissecação, fatores que inferem no processo erosivo através do escoamento superficial da água. Segundo Pereira Filho (2009), maiores índices de dissecação representam também maior suscetibilidade à erosão e consequente aporte de sedimentos ao meio aquático.

Como se pode observar abaixo, trata-se de uma microbacia hidrográfica de relevo uniforme e de pouca dissecação, onde grande parte de sua área encontra-se assentada sobre altitudes entre 240 e 280 metros. A tabela 01 apresenta a área ocupada na microbacia pelas diferentes classes altimétricas.

Tabela 01: Área ocupada pelas classes altimétricas.

\begin{tabular}{ccc}
\hline Classe altimétrica (m) & Área (ha) & Área (\%) \\
\hline $220-240$ & 200,0645 & 16,9359 \\
\hline
\end{tabular}




\begin{tabular}{ccc}
\hline $240-260$ & 442,1423 & 37,4277 \\
$260-280$ & 379,3675 & 32,1140 \\
$280-300$ & 157,2044 & 13,3070 \\
$300-320$ & 2,5489 & 0,2154 \\
TOTAL & $1.181,3276$ & 100,0000 \\
\hline
\end{tabular}

As classes altimétricas com maior representatividade, 240-260 e $260-280$ metros, correspondem a cotas médias típicas dos planaltos da bacia do Paraná 3. Outras menores, 220240 metros, estão associadas aos talvegues da microbacia, enquanto as de 280-300 e 300-320 metros, representam linhas de cumeada. A figura 05 a seguir descreve através de um gráfico a distribuição percentual das classes altimétricas para a microbacia do Rio Ipiranga. 
Figura 05: Gráfico do percentual de área ocupada pelas classes altimétricas (ha).

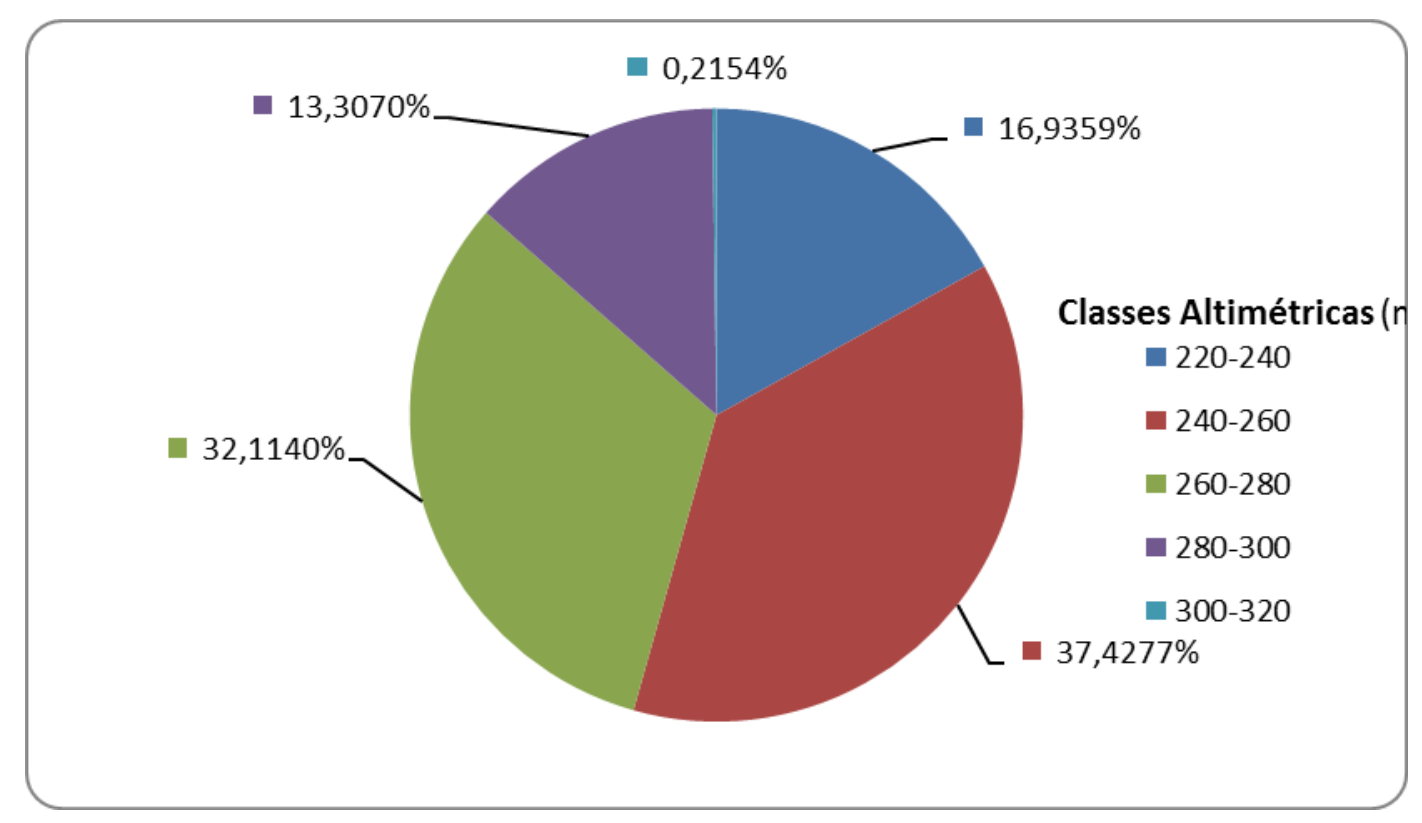

Segundo Rosa e Brito (2003), o mapa de declividade constitui um instrumento de apoio no planejamento de uso de práticas e equipamentos agrícolas mecanizados, além de poder ser utilizado em análises de estrutura agrária e geomorfologia.

A preocupação com o declive relacionado ao uso do solo também é evidenciada no trabalho de Souza et al. (2006), que utiliza a declividade como um dos parâmetros para definir as Classes de Risco Ambiental do Solo, uma vez que as terras declivosas são suscetíveis à erosão e possuem limitações para que sejam utilizadas sem acarretar em degradação ambiental.

Neste mapa foram utilizadas classes de declividade propostas pela Empresa Brasileira de Pesquisa Agropecuária - EMBRAPA (1999), sendo: relevo plano (0 a 3\%), relevo suave-ondulado (3 a 8\%), relevo medianamente inclinado (8 a 12\%), relevo ondulado (12 a 20\%), relevo fortemente ondulado (20 a 45\%) e maior que 45\% (Área de Preservação Permanente). Estas também são as mesmas utilizadas por Souza et al. (2006) na associação da declividade ao risco ambiental para uso do solo.

A tabela 02 apresenta a área ocupada pelas classes de declividade, onde se percebe a maior parte encontrando-se em relevo de pouca inclinação, entre 0 a $3 \%$ e 3 a $8 \%$, sendo situações propicias as práticas agrícolas. A figura 06 apresentada na sequência em forma de gráfico ilustra o percentual de terras da microbacia dentro de cada classe de declividade.

Tabela 02: Área ocupada pelas classes de declividade. 


\begin{tabular}{ccc}
\hline Classes de Declividade (\%) & Área (ha) & Área (\%) \\
\hline $0-3$ & 502,4489 & 42,5326 \\
$3-8$ & 612,5833 & 51,8555 \\
$8-12$ & 56,8778 & 4,8146 \\
$12-20$ & 9,4176 & 0,7973 \\
TOTAL & 1181,3276 & 100,0000 \\
\hline
\end{tabular}

Figura 06: Gráfico do percentual de terras nas classes de declividade (ha).

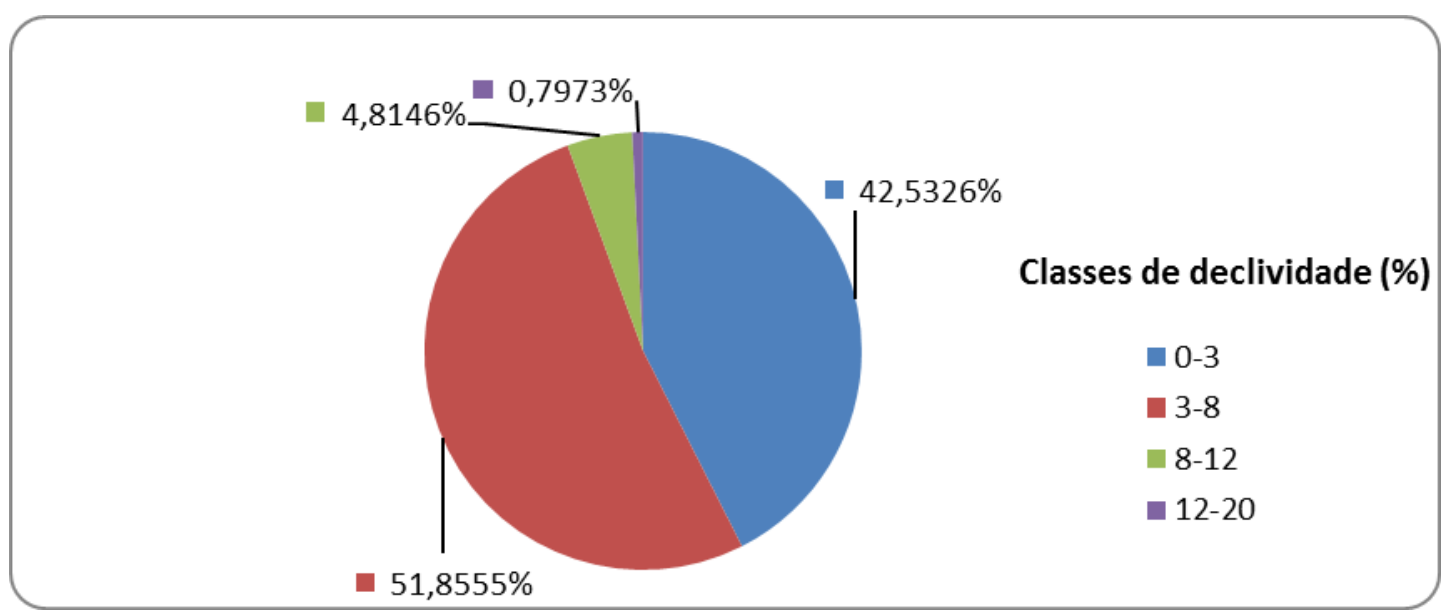

As vertentes da microbacia apresentam-se sob planos suave ondulados em quase toda sua extensão, e as áreas de maior declividade estão associadas às margens do rio.

Os resultados da classificação do uso do solo serviram como uma fonte de dados estatísticos que são apresentados a seguir, na tabela 03 da proporção de áreas, em hectares, para os usos classificados, bem como na figura 07 apresentada na forma de gráfico do percentual de cada uso para o cenário encontrado de ocupação.

Tabela 03: Proporção dos usos do solo da microbacia hidrográfica do Rio Ipiranga.

\begin{tabular}{ccc}
\hline Uso do solo & Área (ha) & Área (\%) \\
\hline Agricultura & 965,7700 & 81,7529 \\
Florestas & 103,6836 & 8,7769 \\
Área Urbana & 37,4813 & 3,1728 \\
Pastagens & 54,7345 & 4,6333 \\
Sedes e Edificações de Propriedades Rurais & 9,5912 & 0,8119 \\
Água & 7,3432 & 0,6216 \\
Estradas & 2,7238 & 0,2306 \\
\hline
\end{tabular}

Revista Brasileira de Energias Renováveis, v. 4, p. 18-31, 2013 


TOTAL $1.181,3276$

Zoneamento climático para região de estudo:

Considerando as exigências térmicas e hídricas da soja conforme tabela 04 e com base nas informações do balanço hídrico de acordo com a tabela 05 abaixo:

Tabela 04: Exigências térmicas e hídricas da soja

\begin{tabular}{cc}
\hline & \\
\hline Necessidade de água no ciclo da soja & 450 a $800 \mathrm{~mm} /$ ciclo \\
Estádio fenológico R1-R5/R6 & 120 a $300 \mathrm{~mm}$ \\
Temperatura para adaptação da soja & $20^{\circ} \mathrm{C} \mathrm{e} 30^{\circ} \mathrm{C}$ \\
Crescimento vegetativo & $>10^{\circ} \mathrm{C}$ \\
Floração da soja R1 & $>13^{\circ} \mathrm{C}$ \\
\hline
\end{tabular}

Tabela 05: Informações do balanço hídrico da região de Foz do Iguaçu.

\begin{tabular}{cccccccc}
\hline Meses & $\mathrm{N}^{\mathrm{o}}$ & $\mathrm{T}{ }^{\mathrm{o}} \mathrm{C}$ & $\mathrm{P}$ & $\begin{array}{c}\text { ETP } \\
\text { Thornthwaite }\end{array}$ & $\begin{array}{c}\text { ETR } \\
(\mathrm{mm})\end{array}$ & $\begin{array}{c}\text { DEF } \\
(\mathrm{mm})\end{array}$ & $\begin{array}{c}\text { EXC } \\
(\mathrm{mm})\end{array}$ \\
\hline Dias & & & 1948 & & & \\
\hline Fev & 28 & 25,5 & 191,0 & 127,96 & 128,0 & 0,0 & 63,0 \\
Mar & 31 & 23,8 & 184,0 & 116,02 & 116,0 & 0,0 & 68,0 \\
Abr & 30 & 20,8 & 146,0 & 78,26 & 78,3 & 0,0 & 67,7 \\
Mai & 31 & 17,8 & 135,0 & 53,90 & 53,9 & 0,0 & 81,1 \\
Jun & 30 & 14,9 & 137,0 & 33,61 & 33,6 & 0,0 & 103,4 \\
Jul & 31 & 14,5 & 90,0 & 32,41 & 32,4 & 0,0 & 57,6 \\
Ago & 31 & 15,9 & 111,0 & 41,10 & 41,1 & 0,0 & 69,9 \\
Set & 30 & 17,7 & 142,0 & 53,53 & 53,5 & 0,0 & 88,5 \\
\hline Out & 31 & 19,3 & 232,0 & 71,36 & 71,4 & 0,0 & 160,6 \\
Nov & 30 & 22,7 & 150,0 & 104,63 & 104,6 & 0,0 & 45,4 \\
\hline Dez & 31 & 23,1 & 171,0 & 116,66 & 116,7 & 0,0 & 54,3 \\
\hline TOTAIS & & 241,4 & 1877,0 & 969,35 & 969,3 & 0,0 & 907,7 \\
\hline MÉDIAS & & 20,1 & 156,4 & 80,78 & 80,8 & 0,0 & 75,6 \\
\hline & & & & & & & \\
\hline
\end{tabular}

Para representar a maioria das cultivares de soja recomendadas para a região, foram 
eleitas duas cultivares hipotéticas, denominadas de precoce com ciclo de 120 dias e tardia com ciclo de 130 dias (FARIAS, J.R.B. et al 2001). Segundo a Portaria ${ }^{\circ}$ 80, de 30.9.2003, publicada no DOU de 2.10.2003, a semeadura da soja tem um período amplo, mais, considerando para o município de Santa Terezinha de Itaipu (PR) região com solo Tipo 3, ou seja, Podzólicos Vermelho-Amarelo e Vermelho Escuro (Terra Roxa Estruturada); Latossolos Roxo e Vermelho Escuro (com mais de 35\% de argila); o período para plantio se define para cultivar precoce de $1^{\circ}$ de Outubro a 31 de Dezembro e para cultivar tardia o período se define de $1^{\circ}$ de Outubro até a primeira dezena de Dezembro.

Segundo Embrapa 2010, a disponibilidade de água é fundamental, em dois períodos de desenvolvimento da soja: germinação-emergência e floração- enchimento de grãos. A necessidade de água na cultura da soja vai gradativamente aumentando com o desenvolvimento da planta, atingindo o ápice durante seu estádio fenológico R1-R5/R6, isto é, na floração-enchimento de grãos (120 a 300 mm), diminuindo após esse período. Déficits hídricos, durante a floração e o enchimento de grãos, estimulam alterações fisiológicas na planta, como o fechamento estomático e o enrolamento de folhas e, como consequência, causam a queda prematura de folhas e de flores e abortamento de vagens, consequentemente ocasionam a redução do rendimento de grãos. A necessidade total de água na cultura da soja, para obtenção do máximo rendimento, varia entre 450 a $800 \mathrm{~mm} / \mathrm{ciclo}$, dependendo das condições climáticas, do manejo da cultura e da duração do ciclo. A soja melhor se adapta a temperaturas do ar entre $20 \mathrm{oC}$ e $30 \mathrm{oC}$. O crescimento vegetativo da soja é pequeno ou nulo a temperaturas menores ou iguais a 10oC. A floração da soja somente é induzida quando ocorrem temperaturas acima de $13 \mathrm{oC}$.

Em trabalhos realizados em Londrina-PR, ao longo de 15 safras, avaliando-se diversas cultivares sob condições distintas de disponibilidade hídrica, verificou-se que os maiores índices de rendimentos de grãos de soja foram obtidos com 650 a $700 \mathrm{~mm}$ de água, bem distribuídos em todo o ciclo. Por outro lado, o excesso de chuva e dias nublados podem interferir a fotossíntese, o arejamento do solo, o desenvolvimento das raízes e a fixação de nitrogênio, reduzindo o rendimento de grãos. O volume de água ideal para atender as necessidades da cultura da soja durante a fase crítica (R1-R6) situou-se entre 120 a $300 \mathrm{~mm}$. Desta forma, ficou evidente que, para garantir máximo rendimento de grãos, o volume de água necessário deve ser disponibilizado ao longo de todo o ciclo, a fim de atender as exigências da cultura, podendo ser suprido através da chuva, da irrigação e/ou do armazenamento de água pelo solo. (Embrapa 2010).

Sendo assim, observa-se que o município de Santa Terezinha de Itaipu (PR) revela-se 
apto para o cultivo de soja precoce e/ou tardia em relação as necessidades térmicas e hídricas, pois, todos os parâmetros indicados na tabela 04 são atendidos de acordo com o balanço hídrico da região de estudo conforme tabela 05.

Além da disponibilidade hídrica, outros fatores devem ser considerados para avaliar a viabilidade da exploração desta cultura com sucesso numa dada região e, principalmente, aumentar a densidade de dados para incrementar a precisão espacial das recomendações.

As informações geradas por este trabalho devem ser utilizado com cautela, levando em conta as características particulares de cada produtor e/ou região, buscando assim o refinamento destas informações, principalmente, no que diz respeito à escala de trabalho. Este trabalho deve ser também, constantemente atualizado com dados de precipitação mais recentes e aprimorado, levando em conta todo o conhecimento acumulado pelo cultivo da soja nas diferentes regiões há vários anos.

\section{Conclusão}

As características da microbacia do rio Ipiranga estão associadas a características naturais de microbacias com baixo potencial de degradação ambiental, microbacia hidrográfica de relevo uniforme e de pouca dissecação, apresentando classes de declividade pouca inclinação, entre 0 a $3 \%$ e 3 a $8 \%$, sendo situações propicias as práticas agrícolas.

O município de Santa Terezinha de Itaipu (PR) revela-se apto para o cultivo de soja precoce e/ou tardia em relação as necessidades térmicas e hídricas, pois, todos os parâmetros indicados neste estudo são atendidos de acordo com o balanço hídrico da região. 


\section{Referências Bibliográficas}

CAMARGO, A.P. Balanço hídrico no Estado de São Paulo. Campinas: IAC, 1971. 28p. (Boletim Técnico, 116).

CAMARGO, A.P.; PINTO, H.S.; PEDRO JR., M.J.; et al. Aptidão climática de culturas agrícolas. In: São Paulo, Secretaria da Agricultura. Zoneamento Agrícola do Estado de São Paulo. São Paulo, v.1, p.109-149, 1974.

CAMARGO, A.P; PEREIRA, A.R. Prescrição de rega por modelo climatológico. Campinas: Fundação Cargill, 1990. 27p.

CAMARGO, M.B.P.; CAMARGO, A.P. Representação gráfica informatizada do extrato do balanço hídrico de Thornthwaite \& Mather. Bragantia, Campinas, v.52, p.169-172, 1993.

CHRISTOFOLETTI, A. Geomorfologia. São Paulo: Ed. Edgard Blucher, 1980.

DOORENBOS, J.; KASSAM, A.H. Efeito da água no rendimento das culturas. Estudos FAO, Irrigação e Drenagem 33. Tradução Gheyi, H.R. e outros, UFPB, Campina Grande. FAO. 306p. 1994.

EMBRAPA, Empresa Brasileira de Pesquisa Agropecuária. Sistemas de Produção Tecnologias de Produção de Soja - Região Central do Brasil 2011. Embrapa Soja Londrina, PR 2010.

EMBRAPA, Empresa Brasileira de Pesquisa Agropecuária. Sistema brasileiro de classificação de solos. Brasília: EMBRAPA, Produção de Informação,1999.

FARIAS, J.R.B. et al. - Caracterização de risco de déficit hidríco nas regiões produtoras de soja no Brasil. Revista Brasileira de Agrometeorologia, Passo Fundo, v.9, n.3, (Nº Especial: Zoneamento Agrícola),p.415-421, 2001.

FARIAS, J.R.B., NEUMAIER, N., NEPOMUCENO, A.L. Impactos da seca na produção de soja. In: REUNIÃO DE PESQUISA DE SOJA DA REGIÃO SUL, 10., 1992, Chapecó. Ata e Resumos...Chapecó: EPAGRI, 1993. p.169.

HORTON, R.E. Erosional development of streams and their drainage basins: a hydrophysical approach to quantitative morphology. Geol Soe. Am. Bull., v.56, n.3, p.275-370, 1945.

JENSEN, N.E. Water consumption by agriculture plants. In: KOZLOWSKI, T.T. (ed) Water deficits and plant growth. New York, Academic Press, 1968. V.2, p.1-22.

LIMA, W. DE PAULA-UNIVERSIDADE DE SÃO PAULO. Introdução de Manejo de Bacias Hidrográficas. São Paulo, 1996.

ORTOLANI, A.A.; PINTO H.S.; PEREIRA, A.R.; ALFONSI, R.R. Parâmetros climáticos e a cafeicultura. Instituto Brasileiro do Café, 1970. 27p.

PALHARES, J. M. Paraná: aspectos da geografia com fundamentos de geografia do Brasil. 
Foz do Iguaçu: GRASMIL, 2000.

PEDRO JÚNIOR, M.J.; MELLO, M.H.A.; PEZZOPANE, J.E.M. Caracterização agroclimática da microbacia: Alto Curso do Ribeirão São Domingos (Pindorama). Campinas, Instituto Agronômico, 1994. 27p. (Boletim Técnico, 150)

PEREIRA FILHO, W. Uma proposta de seleção de critérios para estudo de alterações ambientais através de imagens orbitais. Disponível em: <marte.dpi.inpe.br >. Acesso em: 28 de março de 2009.

PEREIRA, A.R.; VILLA NOVA, N.A.; SEDIYAMA, G.C. Evapo(transpi)ração. Piracicaba: FEALQ, 1997. 183p.

Portaria $\mathrm{n}^{\circ}$ 80, de 30.9.2003, publicada no DOU de 2.10.2003. Zoneamento Agrícola do Ministério da Agricultura, Pecuária e Abastecimento. PARANÁ SOJA Safra 2003/2004.

RODRIGUES, C.; ADADI, S. Técnicas Fundamentais para o estudo de Bacias Hidrográficas. In: Venturi Luis A.B. Praticando a Geografia: técnicas de campo e laboratório em geografia e análise ambiental. São Paulo: Oficina de textos, 2005, p. 147-166.

RODRIGUES, S.P.; Diagnóstico local do município de Santa Terezinha de Itaipu. PREFEITURA MUNICIPAL DE SANTA TEREZINHA DE ITAIPU. SECRETARIA MUNICIPAL DE SAÚDE. 2007.

ROSA, R.; BRITO, J. L. S. Mapa hipsométrico e de declividade do terreno da bacia hidrográfica do Rio Araguari - MG. In: II Simpósio Regional de Geografia - Perspectivas para o cerrado no século XXI. Uberlândia, 2003.

SCHIAVETTI, A. O estudo de bacias hidrográficas, uma estratégia para educação ambiental. São Carlos: Rima, 2003.

SILVA, Maria Sebastiana; NAVES, Maria Margareth V.; OLIVEIRA, Rosicler B. de and LEITE, Oneide de S. M.. Composição química e valor protéico do resíduo de soja em relação ao grão de soja. Ciênc. Tecnol. Aliment. [online]. 2006, vol.26, n.3, pp. 571-576. ISSN 1678$457 X$.

SOUZA, M. L. P.; BLEY JR, C. J.; SOUZA, L. C. P. Classificação do risco ambiental das terras e sua utilização no cadastro técnico multifinalitário. In: Congresso Brasileiro de Cadastro Técnico Multifinalitário - COBRAC, Florianópolis, 2006.

STRAHLER, Arthur N. Quantitative geomorphology of drainage basins and chanel networks. In: CHOW, V. T. (ed.). Handbook of applied hydrology. New York: Mc-GrawHill, 1964. THORNTHWAITE, C.W.; MATHER, J.R. The water balance. Publications in Climatology. New Jersey: Drexel Institute of Technology, 104p. 1955. 
VIANELLO, R.L.; ALVES, A.R. Meteorologia básica e aplicações. Viçosa, UFV, 1991, 449 p. 